\title{
Indicadores para la evaluación de la calidad en cibermedios: análisis de la interacción y de la adopción de la Web 2.0
}

\author{
Ruth Rodríguez-Martínez*, Lluís Codina*, Rafael Pedraza-Jiménez*
}

Resumen: La creciente adaptación de los medios de comunicación al entorno digital hace conveniente la utilización de metodologías de análisis que permitan determinar la calidad de sus sitios web. En este artículo, a partir del estudio de las características de las webs de algunos de los medios de comunicación más importantes a nivel internacional, se propone una metodología para la evaluación específica de este tipo de sitios web. El modelo propuesto se compone de treinta y seis indicadores, organizados en torno a ocho parámetros que permiten valorar, especialmente, la adaptación del medio de comunicación a la interacción de la Web 2.0. Otros aspectos a los que también se presta atención, pero en menor medida, son la arquitectura de la información, la usabilidad, la accesibilidad o las herramientas de interacción y comunicación que éste pone a disposición de sus usuarios.

Palabras clave: Análisis y evaluación de recursos digitales, metodología de análisis y evaluación, indicadores, medios de comunicación, cibermedios, Web 2.0, cooperación, interacción, socialización, calidad del contenido, participación.

\section{Indicators to evaluate the quality of online journalism web sites: an analysis of Web 2.0 interaction and adoption}

Abstract: Due to the increasing adaptation made by the mass media to the Web scenario, there is need for a methodology to allow us to analyze and evaluate the quality of news websites. Based on a study of the characteristics of the websites of the major news media, this article proposes a specific methodology for the evaluation of this sort of website. The proposed methodology consists of thirty-six indicators, organized around eight parameters that evaluate, mainly, the degree of adaptation of the media to Web 2.0 interaction. Apart from that, other aspects are evaluated, such as information architecture, accessibility, usability and the interaction and communication tools offered to users.

Keywords: Analysis and evaluation of digital resources, methodology of analysis and evaluation, indicators, media, online media, news websites, Web 2.0, cooperation, interaction, socialization, content quality, participation

* Universitat Pompeu Fabra, Barcelona. Correo-e: ruth.rodriguez@upf.edu, lluis.codina@upf.edu, rafael.pedraza@upf.edu.

Recibido:21-04-2011; 2. ${ }^{\mathrm{a}}$ versión: 07-07-2011; aceptado:18-07-2011. 


\section{Introducción}

El entorno generado a raíz de la aparición y consolidación de la Web 2.0 ha cambiado la manera en la cual los sitios web de los medios de comunicación (cibermedios a partir de ahora) ponen el contenido a disposición de los usuarios (Glocer, 2006; López García, 2008). Este artículo tiene como objetivo presentar un conjunto de indicadores que pueden ser útiles para la evaluación del nivel de adaptación de los cibermedios a la Web actual (Pew Research Center, 2011), haciendo especial énfasis en la interacción (Schutz, 1999) (de la cual la personalización es uno de sus aspectos destacados), pero incluyendo también aspectos relevantes de usabilidad y arquitectura de la información. El motivo es que entendemos que la merecida atención a los aspectos de la Web 2.0 y la nueva interacción que promueven, no debería eliminar el interés por componentes vinculados con la usabilidad y la arquitectura de la información.

Para obtener los indicadores que se presentarán a continuación se llevó a cabo una labor de análisis de los principales cibermedios españoles e internacionales (Rodríguez-Martínez y otros, 2010). Naturalmente, para analizar, es necesario disponer de instrumentos de análisis, pero el objetivo de este trabajo era conseguir estos instrumentos de análisis: un pez que se muerde la cola.

Para resolver este problema se adoptó un triple punto de partida: en primer lugar se tomaron como objeto de estudio preferente (pero no exclusivamente, como ya hemos indicado) los aspectos de los cibermedios relacionados con la Web 2.0, entre otras, la interacción y la personalización, ya que otras cuestiones de la Web "convencional» ya han sido reiteradamente tratadas. En segundo lugar se procedió a realizar un mapeo de funciones presentes en los medios analizados, todo ellos medios de referencia. Esto significa que, hasta el momento, ningún medio presenta todas las funciones o características de la Web 2.0; pero un mapeo de las diversas funciones sí nos puede proporcionar el conjunto de esas funciones (no de las funciones posibles en un mundo ideal, sino el conjunto de las funciones en los Cibermedios realmente existentes).

Una vez con el mapa de las funciones, se procedió a documentarlas aplicando una de las metodologías de obtención y de documentación de indicadores más utilizadas en este tipo de estudios (Codina, 2006), incluyendo la idea básica de que los indicadores deben agruparse al menos en parámetros ( $\sin$ perjuicio de otras unidades de agrupación). Asimismo, se han tenido en cuenta los trabajos realizados por Zamith (2008) y Palacios (Palacios y Díaz Noci, 2009), así como los modelos de análisis propuestos por Rodríguez-Martínez y otros (2009) y Guallar y Abadal, 2009).

Una metodología de análisis como la que presentamos aquí, entendemos que puede ser aplicada en escenarios como los siguientes:

- Escenario 1: evaluación de la calidad de los contenidos de los sitios web (Codina, 2000) de los medios de comunicación. Este escenario permite observar tendencias así como establecer parámetros y criterios sobre la calidad 
con la que los medios de comunicación se han adaptado a las necesidades y posibilidades de interacción (Bradshaw, 2008) y personalización que ofrece la Web y, muy especialmente, la Web 2.0.

- Escenario 2: análisis académicos de medios de comunicación. Este tipo de análisis hace posible identificar las características específicas de los sitios web de los medios de comunicación, así como observar sus fortalezas y debilidades. De esta forma se pueden crear pautas o criterios de calidad que sirvan para analizar sitios web del ámbito de la comunicación (Salaverría y otros, 2005).

- Escenario 3: ámbito profesional. Uso de esta propuesta como modelo o referencia para la creación o rediseño de sitios web del ámbito de la comunicación en función de los indicadores de calidad propuestos.

\section{Medios de comunicación en el entorno de la web: escenario, dimensiones, parámetros e indicadores específicos}

El escenario que se estudia para llevar a cabo esta metodología es el contenido facilitado por los sitios web de los medios de comunicación y los recursos digitales que éstos han desarrollado para hacerlos llegar de forma adecuada a sus usuarios. Este escenario, que es específico en la medida en que sólo se refiere al ámbito del periodismo y la comunicación (Díaz Noci, 2005), se puede concretar en las siguientes manifestaciones:

- Los medios de comunicación han adaptado las herramientas y usos propios de la web al contenido de sus sitios web para hacerlos visibles y accesibles a sus usuarios.

- Los medios de comunicación han creado herramientas de tipo Web 2.0 para canalizar contenidos específicos de su disciplina y satisfacer así sus necesidades de comunicación particulares.

- La relación existente entre los medios de comunicación en línea con sitios web que reúnen características propias del entorno Web 2.0 y que gozan de gran aceptación entre los usuarios de Internet (Horrigan, 2006).

El método de evaluación que se propone en el presente trabajo tiene como objetivo establecer dimensiones, parámetros e indicadores que permitan examinar los sitios web del ámbito de la comunicación con el fin de conocer si han hecho o no una adaptación adecuada al entorno de la Web (Díaz Noci y otros, 2009). Para elaborar este conjunto de dimensiones, parámetros e indicadores se han analizado multitud de sitios web de diversos medios de comunicación, entre los que se encuentran: sitios web de diarios internacionales y nacionales (The Bivings Group, 2008; Wurff y otros, 2005), canales de televisión, blogs elaborados por periodistas (Meso, 2008), sitios web de periodismo ciudadano, etc. Entre las fuen- 
tes analizadas se encuentran los sitios web de: The New York Times, The Guardian, El País, El Mundo, La Vanguardia, ABC, El Periódico de Catalunya, El Correo Digital, CNN, BBC, PBS, TVE1, The Christian Science Monitor, My Missourian, The Washington Post y La Información.

Las dimensiones que se han incluido en el presente modelo son las que se exponen a continuación:

- Dimensión 1: cooperación.

- Dimensión 2: participación.

- Dimensión 3: creación de contenido.

- Dimensión 4: acceso al contenido.

- Dimensión 5: socialización.

- Dimensión 6: comunicación.

En lo que se refiere a los parámetros empleados, éstos son los que se proponen para llevar a cabo esta evaluación:

- Parámetro 1: interacción usuario-medio de comunicación.

- Parámetro 2: publicación de contenidos creados por los usuarios.

- Parámetro 3: registro del usuario.

- Parámetro 4: acceso a la información.

- Parámetro 5: canal de contenido personalizado.

- Parámetro 6: el medio ofrece distintas versiones de su información.

- Parámetro 7: empleo de herramientas de la Web 2.0.

- Parámetro 8: plataformas de la Web 2.0 en las que tiene presencia el medio de comunicación.

En total se han identificado 36 indicadores, agrupados en función de los parámetros anteriores. Son los siguientes:

- Parámetro 1: interacción medio de comunicación-usuario. Indicadores:

1.1. Comunicación con el autor de la noticia.

1.2. Contacto con la redacción del medio de comunicación.

1.3. Comentar noticias publicadas por el medio de comunicación.

1.4. Votación de noticias publicadas por el medio de comunicación.

1.5. Comentar entradas publicadas en los blogs del medio de comunicación.

1.6. El usuario puede modificar o corregir contenido publicado por el medio.

- Parámetro 2: publicación de contenidos creados por los usuarios. Indicadores:

2.1. Creación de blogs por los usuarios.

2.2. Publicación de textos escritos por los usuarios. 
2.3. Publicación de fotos tomadas por los usuarios.

2.4. Publicación de vídeos realizados por los usuarios.

2.5. Sección exclusiva para contenido creado por los usuarios.

- Parámetro 3: registro del usuario.

\section{Indicadores:}

3.1. Registro por parte del usuario en el medio.

3.2. Contacto con otros usuarios registrados.

- Parámetro 4: acceso a la información.

\section{Indicadores:}

4.1. Acceso a la información a través de la portada.

4.2. Acceso a la información a través de secciones.

4.3. Acceso a la información a través de noticias relacionadas.

4.4. Acceso a la información a través del buscador.

4.5. Acceso a la información a través del mapa web.

4.6. Acceso a la información a través de la recomendación de los usuarios.

4.7. Acceso a la información a través de plataformas externas de la Web 2.0.

- Parámetro 5: personalización de la información.

Indicadores:

5.1. Adaptación de la interfaz del sitio web del medio de comunicación en función de los contenidos de interés para el usuario.

5.2. Sindicación de contenidos del medio de comunicación a través del móvil o correo electrónico.

5.3. Suscripción de alertas o boletín electrónico.

- Parámetro 6: el medio ofrece distintas versiones de su información.

\section{Indicadores:}

6.1. Versión impresa del medio.

6.2. Versión global.

6.3. Versión actualizada de forma constante.

6.4. Versión impresa adaptada a la Web 2.0.

- Parámetro 7: empleo de herramientas de la Web 2.0. Indicadores:

7.1. Compartir información con otros usuarios.

7.2. Blogs vinculados al medio de comunicación.

- Parámetro 8: plataformas de la Web 2.0 en las que tiene presencia el medio de comunicación.

\section{Indicadores:}

8.1. Presencia del medio de comunicación en plataformas audiovisuales.

8.2. Presencia del medio de comunicación en plataformas de imágenes. 
8.3. Empleo de redes sociales propias.

8.4. Presencia del medio de comunicación en redes sociales profesionales externas.

8.5. Presencia del medio de comunicación en redes sociales de amistad.

8.6. Presencia del medio de comunicación en plataformas de microblogging.

8.7. Vinculación entre el sitio web del medio de comunicación y las plataformas sociales.

Con el fin de facilitar su comprensión y uso se presenta, a continuación, una descripción de los indicadores propuestos. Para cada uno de ellos se facilitan las siguientes informaciones:

- Una descripción detallada del indicador: campo Definición.

- La metodología a seguir para poder evaluar su presencia o ausencia en un sitio web: campo Examen.

- Ejemplos reales de la aplicación del indicador en medios de comunicación en línea: campo Ejemplos.

- El lugar del sitio web donde puede localizarse el indicador: campo Procedimiento.

- La valoración de la importancia del indicador: campo Puntuación. Este campo aparece vacío para todos los indicadores. Esto se debe a que la importancia de cada indicador debe ser asignada por la persona/medio que evalúa el sitio web atendiendo a sus intereses particulares. De esta forma, por ejemplo, el uso de plataformas audiovisuales puede tener gran importancia para un canal de televisión, y una importancia muy reducida para un diario.

- Dimensión o dimensiones (de las descritas anteriormente) dentro de la cual podemos incluir el indicador objeto de análisis: campo Dimensión.

\section{PARÁMETRO 1: interacción medio de comunicación-usuario}

\section{Indicador 1.1: comunicación con el autor de la noticia}

Definición: posibilidad de ponerse en contacto, a través del correo electrónico, con el autor de la noticia publicada por el medio de comunicación.

Examen: ¿Se le da al usuario la posibilidad de enviar un mensaje de correo electrónico al autor de la noticia para ampliar información al respecto?

Ejemplos: en el sitio web del diario The New York Times la mayor parte de los autores de los artículos aparecen vinculados a su dirección de correo electrónico.

http://www.nytimes.com/2010/10/04/business/04borrow.html?_r=1\&hp.

Procedimiento: examen del sitio web. Página donde aparece publicado el texto completo de la noticia.

Puntuación: 0-1.

Dimensión: comunicación. 
FIGURA 1

The New York Times facilita la comunicación directa con el autor de la noticia

\section{Cheap Debt for Corporations Fails}

BY GRAHAM BOWLEY

Published: October 3,2010

\section{Indicador 1.2: contacto con la redacción del medio de comunicación}

Definición: recurso que facilita al usuario la opción de entrar en contacto con los miembros de la redacción del medio de comunicación a través del correo electrónico.

Examen: ¿puede el usuario del medio de comunicación ponerse en contacto a través del correo electrónico con el equipo de redacción del medio de comunicación para conocer solicitar información adicional sobre el contenido publicado?

Ejemplos: el sitio web del diario The New York Times facilita a los usuarios la opción de ponerse en contacto con los editores, periodistas, columnistas y directivos que conforman la plantilla del diario.

http://www.nytimes.com/ref/business/media/asktheeditors.html?scp=2\&sq= newsroom\&st=cse.

Procedimiento: examen del sitio web. Sección específica.

Puntuación: 0-1.

Dimensión: Comunicación.

FIGURA 2

Web del New York Times para contactar con la redacción del diario

Talk to The Times: Q. and A. With Staff Members

Talk to The Times invites readers to submit questions for Times editors, reporters, columnists and executives. If there is a Times staff member you would like to see as a guest in Talk to The Times, please e-mail your suggestion to askthetimes@nytimes.com.

\section{Indicador 1.3: comentar noticias publicadas por el medio de comuni- cación}

Definición: posibilidad que se le ofrece al usuario para que comente las noticias publicadas por el medio de comunicación. Asimismo, se le permite leer y contestar los comentarios hechos por otros usuarios respecto a la misma noticia. El medio puede o no exigir al usuario que se registre previamente antes de poder comentar las informaciones. En los comentarios no aparece la totalidad de la información que se solicita al usuario para llevar a cabo el registro. 
Examen: ¿se permite al lector comentar las noticias a las que tiene acceso y ver los comentarios de otros lectores?

Ejemplos: el sitio web lainformacion.com.

http://www.lainformacion.com.

Procedimiento: examen del sitio web. Página donde aparece publicada la noticia.

Puntuación: 0-1.

Dimensión: participación.

\section{FIGURA 3}

Posibilidad de que los usuarios hagan comentarios a las noticias de lainformacion.com

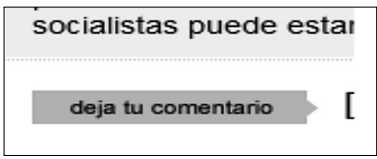

\section{Indicador 1.4: votación de noticias publicadas por el medio de comu- nicación}

Definición: el medio de comunicación permite al usuario votar las informaciones que publica para conocer si éstas han sido o no de su interés. Las votaciones son anónimas y se publica el resultado total de las votaciones realizadas por los usuarios. El sistema de votaciones empleado por cada medio es diferente. Por regla general, un resultado próximo al valor inferior responde a un interés escaso por parte de los usuarios y un resultado cercano al valor superior es indicativo de un alto interés y satisfacción de los usuarios.

Examen: ¿puede el lector votar las informaciones a las que tiene acceso para mostrar su satisfacción o insatisfacción sobre el tratamiento de la noticia dada por el medio?

Ejemplos: en el sitio web del diario El País.

http://www.elpais.com/

Procedimiento: examen del sitio web. Página donde aparece publicado el texto completo de la noticia.

Puntuación: 0-1.

Dimensión: cooperación.

\section{FIGURA 4}

Votación de noticias en el diario "El País"

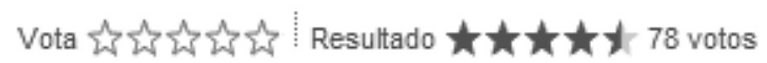




\section{Indicador 1.5: comentar entradas publicadas en los blogs del medio} de comunicación

Definición: el medio de comunicación cuenta con blogs firmados por miembros de su equipo de redacción y ofrece al lector la opción de comentar cada una de las entradas que se publican. Para poder comentar las entradas de los blogs el usuario debe indicar su nombre y dirección de correo electrónico. Este último no aparece en el comentario que se publica. Todos los comentarios son revisados por un equipo editorial antes de ser publicados.

Examen: ¿se permite al usuario comentar las entradas publicadas en los blogs del medio de comunicación?

Ejemplos: el sitio web del canal de televisión $C N N$.

http://ac360.blogs.cnn.com/

Procedimiento: examen del sitio web. Acceso a cada uno de los blogs publicados por los colaboradores del medio de comunicación.

Puntuación: 0-3.

Dimensión: participación.

\section{FIGURA 5}

\section{Blog propio del canal de televisión CNN}

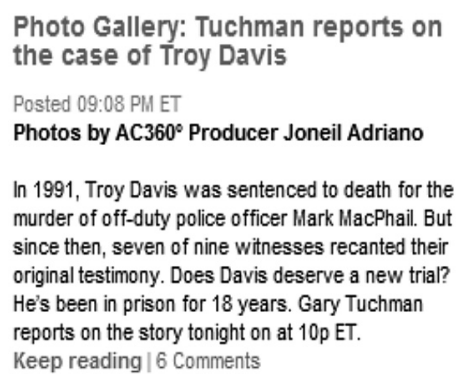

Indicador 1.6: el usuario puede modificar o corregir contenido publicado por el medio de comunicación

Definición: el medio de comunicación permite al usuario corregir aquellas informaciones que puedan ser mejoradas o requieran ser modificadas. Para ello el usuario debe facilitar su nombre y dirección de correo electrónico.

Examen: ¿se permite al usuario corregir las informaciones publicadas por el medio de comunicación?

Ejemplos: el sitio web del diario The Christian Science Monitor.

http://www.csmonitor.com/About/Corrections

Procedimiento: examen del sitio web. Acceso a cada uno de los blogs publicados por los colaboradores del medio de comunicación.

Puntuación: 0-3.

Dimensión: cooperación. 


\section{FIGURA 6}

Sección para el envío de correcciones del diario The Christian Science

\section{Corrections}

The Monitor prompty corrects tactual errors and welcomes comments and information that may call for correction. Please e-mail us with any corrections.

\section{PARÁMETRO 2: publicación de contenidos creados por los usuarios}

\section{Indicador 2.1: creación de blogs por los usuarios}

Definición: los usuarios cuentan con la posibilidad de crear un blog vinculado a la dirección (URL) del medio de comunicación. El medio de comunicación no se hace responsable del contenido publicado en este tipo de blogs y se reserva el derecho de suspender aquellos blogs que no cumplan las normas establecidas por el medio.

Examen: ¿puede el usuario crear un blog vinculado al medio de comunicación?

Ejemplos: el sitio web del diario El País.

http://lacomunidad.elpais.com/

Procedimiento: examen del sitio web. Página de inicio.

Puntuación: 0-1.

Dimensión: participación.

\section{FIGURA 7}

Sección del diario El País para que sus lectores creen su propio blog

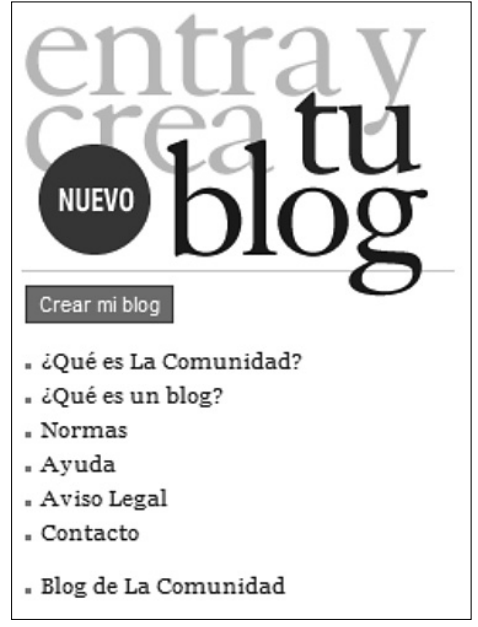




\section{Indicador 2.2: publicación de textos escritos por los usuarios}

Definición: los medios de comunicación publican textos redactados por sus usuarios. Los textos son revisados por un equipo editorial antes de ser publicados. El medio de comunicación pone en conocimiento del usuario los criterios que debe seguir para redactar los contenidos.

Examen: ¿tiene la posibilidad el usuario de enviar textos al medio de comunicación para que éste lo publique?

Ejemplos: MyMissourian, sitio web de periodismo ciudadano en la que los usuarios pueden enviar textos para su posterior publicación.

http://mymissourian.com/

Procedimiento: examen del sitio web. Página de inicio.

Puntuación: 0-3.

Dimensión: participación.

FIGURA 8

Publicación en el diario MyMissourian de informaciones escritas por sus lectores

\begin{tabular}{|c|c|}
\hline Grassroots Jourr & lism for Mic \\
\hline $\begin{array}{l}\text { All content on MyMissourian } \\
\text { comes from stories } \\
\text { submitted by you! Click on }\end{array}$ & $\begin{array}{l}\text { Small world } \\
\text { July } 20,2009\end{array}$ \\
\hline
\end{tabular}

Indicador 2.3: publicación de fotos tomadas por los usuarios

Definición: el medio de comunicación permite que los usuarios envíen fotos para que sean publicadas en su sitio web. Antes de enviar este material gráfico el usuario debe estar registrado en el sitio web del medio.

Examen: ¿se permite al usuario enviar fotos al medio de comunicación para que sean publicadas?

Ejemplos: sitio web del diario El Correo Digital.

http://www.elcorreo.com/vizcaya/participa/

Procedimiento: examen del sitio web. Página de inicio.

Puntuación: 0-1.

Dimensión: participación. 


\section{FIGURA 9}

Publicación de fotografías realizadas por los lectores en el diario El Correo Digital

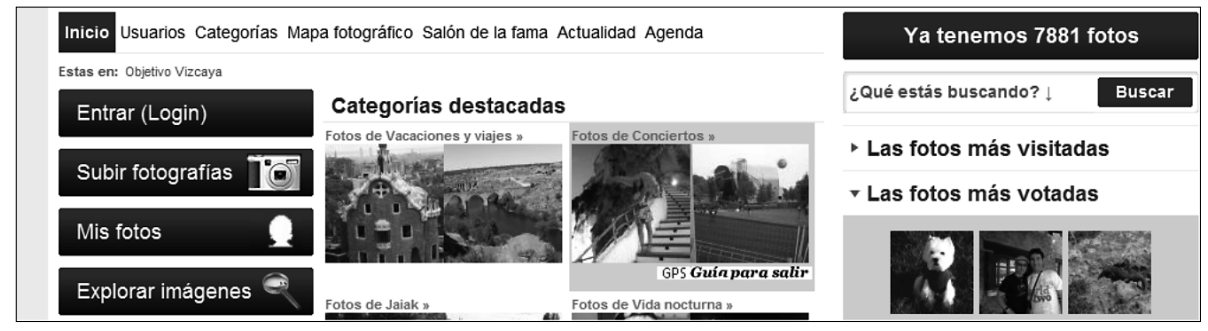

\section{Indicador 2.4: publicación de vídeos realizados por los usuarios}

Definición: los usuarios tienen la posibilidad de enviar vídeos para que éstos sean publicados en el sitio web del medio de comunicación. Es preciso que el usuario facilite datos de identificación personales, públicos y privados, antes de proponer material audiovisual al medio.

Examen: ¿es posible que el usuario publique vídeos realizados por él mismo en el sitio web de un medio de comunicación?

Ejemplos: sitio web del diario de El Periódico de Catalunya.

http://tusimagenes.elperiodico.com/enviar.php

Procedimiento: examen del sitio web. Página de inicio.

Puntuación: 0-1.

Dimensión: participación.

\section{FIGURA 10}

Publicación de videos realizados por los lectores en el diario El Periódico de Catalunya

\begin{tabular}{|l|l|}
\hline 6.8. TUS VIDEOS & BUSCAR \\
\hline ENVIO DE FOTOS O VIDEOS \\
\hline $\begin{array}{l}\text { Rellene el formulario con los datos y adjunte su imagen (fotografia o vídeo). EL PERIÓDICO utilzará los datos } \\
\text { personales (dirección de correo electrónico y teléfono) para ponerse en contacto con los ganadores del } \\
\text { concurso. Recomendamos a los lectores que limiten sus envíos a } 5 \text { fotos y un vídeo por usuario y día, para } \\
\text { evitar penalizar la participación de otros usuarios. }\end{array}$ \\
\hline
\end{tabular}

\section{Indicador 2.5: sección exclusiva para contenido creado por los usuarios}

Definición: el medio de comunicación cuenta con una sección dedicada en exclusiva para la publicación de contenido generado por los usuarios. El tipo de contenido que los usuarios pueden proponer para esta sección es: textual, gráfico o audiovisual. 
Examen: ¿existe una sección en el medio de comunicación dedicada a contenido enviado por los usuarios?

Ejemplos: sección Participación del sitio web del diario La Vanguardia.

http://www.lavanguardia.es/

Procedimiento: examen del sitio web. Página de inicio.

Puntuación: 0-3.

Dimensión: participación.

\section{FIGURA 11}

El diario La Vanguardia dispone de una sección específica para la publicación de contenidos aportados por sus lectores

\section{LAVANGUARDIA.eS \\ 4 de octubre 2010 \\ \begin{tabular}{|l|l|l|l|l|l}
\hline INICIO & SERVICIOS & PARTICIPACIÓN & FOTOS I VIDEOS I BLOGS & HEN
\end{tabular}}

\section{PARÁMETRO 3: registro del usuario}

\section{Indicador 3.1: registro por parte del usuario en el medio}

Definición: el medio de comunicación ofrece a los usuarios la posibilidad de registrarse. Para ello los usuarios deben facilitar su nombre y dirección de correo electrónico. Esto permite a los usuarios comentar y votar las informaciones, recomendar la lectura de informaciones, enviar material al medio para que éste lo publique, etc.

Examen: ¿cuenta el usuario con la posibilidad de registrarse en el medio para que éste le identifique?

Ejemplos: el sitio web El País permite a los usuarios registrarse y les explica de forma breve las ventajas de ser usuario registrado.

https://plus.elpais.com/clientes2/registro/conectar.html?prod=REG

Procedimiento: examen del sitio web. Página de inicio.

Puntuación: $0-3$.

Dimensión: acceso al contenido.

FIGURA 12

Registro de usuario en el diario El País

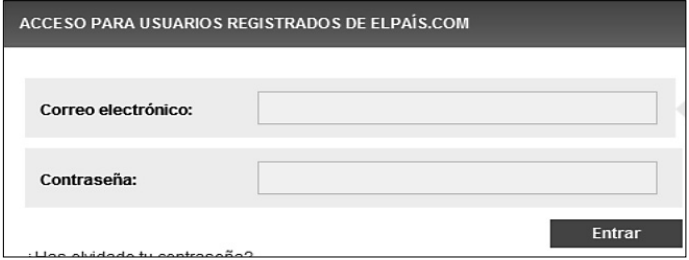




\section{Indicador 3.2: contacto con otros usuarios registrados}

Definición: los usuarios registrados en el medio de comunicación forman una comunidad de usuarios registrados que pueden interactuar entre sí.

Examen: ¿puede comunicarse el usuario registrado con otros que también lo están?

Ejemplos: el sitio web del diario The New York Times permite al usuario registrado ponerse en contacto con otros usuarios registrados con los que constituye una comunidad.

http://www.nytimes.com/

Procedimiento: examen del sitio web. Página de registro.

Puntuación: 0-1.

Dimensión: comunicación.

\section{FIGURA 13}

TimesPeople es un espacio del sitio web del diario The New York Times que permite a sus lectores comunicarse e interactuar entre sí

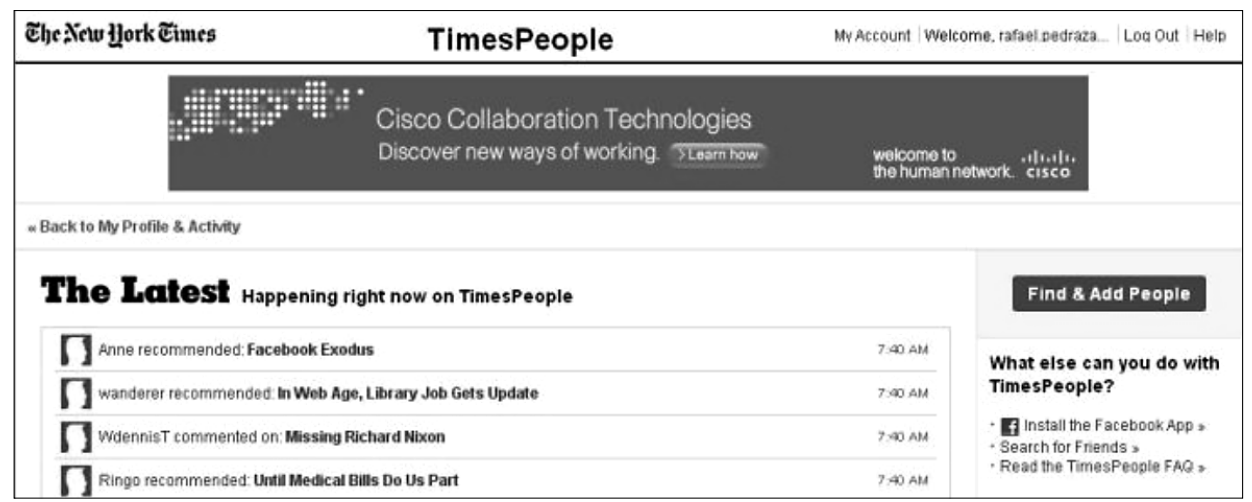

\section{PARÁMETRO 4: acceso a la información}

\section{Indicador 4.1: acceso a la información a través de la portada}

Definición: el medio de comunicación permite que el usuario tenga la posibilidad de acceder a la mayor parte de las noticias que publica a través de la portada o página de inicio de su sitio web.

Examen: ¿puede el usuario acceder a las noticias a través de la página de inicio de su sitio web?

Ejemplos: el sitio web del diario $A B C$.

http://www.abc.es/

Procedimiento: examen del sitio web. Página de inicio.

Puntuación: 0-3.

Dimensión: acceso al contenido. 


\section{FIGURA 14}

Imagen de la portada del sitio web del diario $A B C$

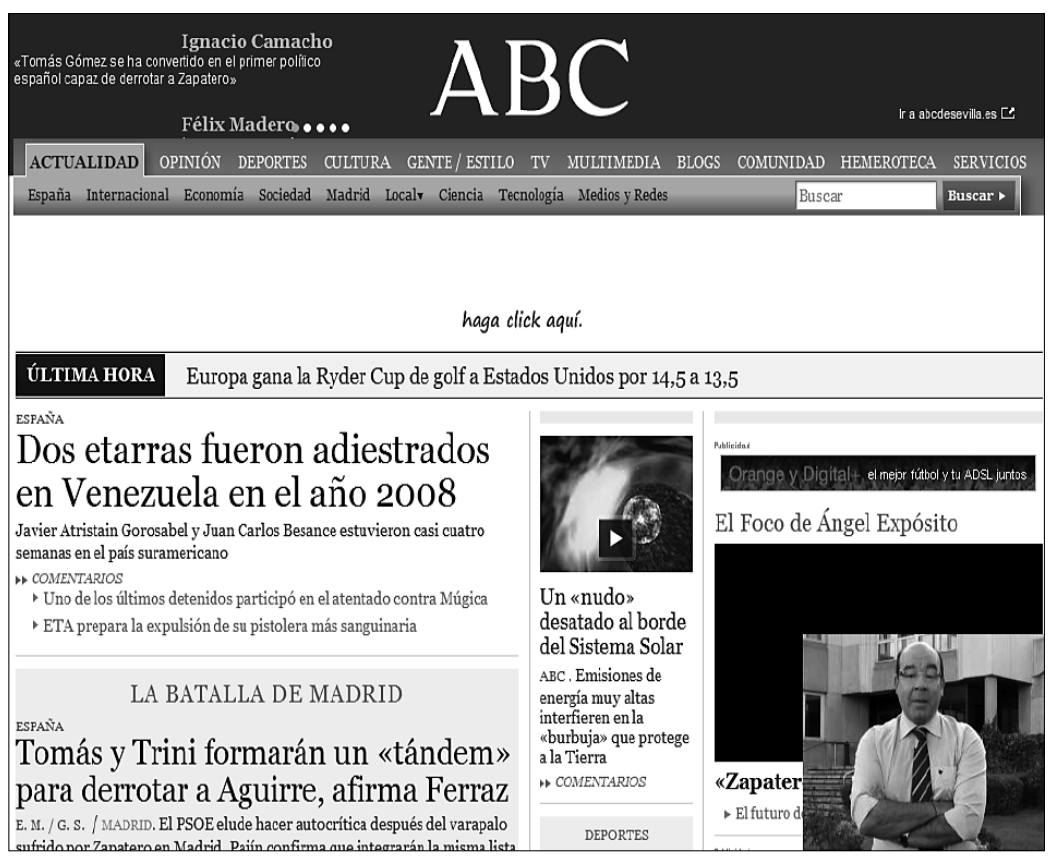

\section{Indicador 4.2: acceso a la información a través de secciones}

Definición: el sitio web del medio de comunicación clasifica las distintas noticias que pone a disposición de sus usuarios de acuerdo con una jerarquía de secciones que se mantiene fija. En el caso de los sitios web de diarios estas secciones guardan cierta relación con las que aparecen en sus versiones impresas.

Examen: ¿puede el usuario acceder a noticias de una misma temática a través de las distintas secciones de su sitio web?

Ejemplos: el sitio web del diario The Guardian.

http://www.guardian.co.uk/

Procedimiento: examen del sitio web. Secciones del diario.

Puntuación: 0-3.

Dimensión: acceso al contenido.

\section{FIGURA 15}

Secciones que aparecen en el sitio web del diario The Guardian

\begin{tabular}{|l|l|l|l|l|l|l|l|l|l|l|l|l|}
\hline News & Sport & Comment & Culture & Business & Money & Life \& style & Travel Environment & TV & Video & Community & Blogs & Jobs
\end{tabular}

News UK World Development US Politics Media Education Society Science Tech Law Football Guardian Observer 


\section{Indicador 4.3: acceso a la información a través de noticias relacionadas}

Definición: el usuario accede a la página donde aparece la información que es de su interés al tiempo que se le facilitan enlaces a otras noticias de temática similar

Examen: ¿puede el usuario encontrar noticias de temática similar desde la página donde encuentra la noticia que es de su interés?

Ejemplos: el sitio web de $E l$ periódico.

http://www.elperiodico.com/es/

Procedimiento: examen del sitio web. Página donde aparece publicado el texto completo de la noticia.

Puntuación: 0-3.

Dimensión: acceso al contenido.

\section{FIGURA 16}

Enlaces a noticias relacionadas con la temática de la información que se consulta

\begin{tabular}{|c|c|}
\hline \multicolumn{2}{|c|}{$\begin{array}{l}\text { más que en agosto. El pasado junio habia } 4.066 .000 \text { de par } \\
\text { en julio. }\end{array}$} \\
\hline Más información & En un añd \\
\hline $\begin{array}{l}\text { Cae la confianza de los consumidores por la } \\
\text { evolución de la situación económica } \\
\text { La Seguridad Social pierde } 44.985 \text { afiliados }\end{array}$ & $\begin{array}{l}\text { un } 8, \%, \text { s } \\
\text { Trabajo. } \\
\text { en } 1.374\end{array}$ \\
\hline \multicolumn{2}{|l|}{ Tags: Economia } \\
\hline el sector servicios, una & $\begin{array}{l}\text { Por secto } \\
\text { abada la tel }\end{array}$ \\
\hline
\end{tabular}

\section{Indicador 4.4: acceso a la información a través del buscador}

Definición: El medio de comunicación permite que el usuario busque aquella información que es de su interés a través de un buscador. Este buscador se encuentra de manera habitual en la página de inicio del sitio web. El tipo de búsqueda que puede hacer el usuario puede ser simple o avanzada. En este último caso, el usuario puede hacer un filtro de noticias de acuerdo con diversos parámetros, entre otros: fecha, formato, género, sección, etc.

Examen: ¿puede el usuario buscar noticias que contengan uno o más términos de su interés?

Ejemplos: el sitio web del diario Le Monde.

http://www.lemonde.fr/

Procedimiento: examen del sitio web. Página de inicio.

Puntuación: 0-3.

Dimensión: acceso al contenido. 


\section{FIGURA 17}

Imagen del buscador que pone a disposición de los usuarios el sitio web del diario Le Monde

\begin{tabular}{|l|l|}
\hline Recherchez sur Le Monde.fr $\rho$ & $\rho$ \\
\hline
\end{tabular}

\section{Indicador 4.5: acceso a la información a través del mapa web}

Definición: el medio de comunicación facilita al usuario el acceso a la información a través de un mapa de su sitio web, normalmente ubicado en la página de inicio del sitio web. Este mapa clasifica las informaciones por temáticas, fechas, suplementos, herramientas o servicios.

Examen: ¿puede el usuario acceder a las noticias a través de un mapa de su sitio web?

Ejemplos: el sitio web del diario El Mundo.

http://www.elmundo.es/mapadelsitio/

Procedimiento: examen del sitio web. Página de inicio.

Puntuación: 0-1.

Dimensión: Acceso al contenido.

\section{FIGURA 18}

Imagen del mapa web del sitio web del diario El Mundo

\begin{tabular}{|c|c|c|}
\hline \multirow{2}{*}{\multicolumn{3}{|c|}{$\begin{array}{l}\text { Portada }>\text { Mapa del sitio } \\
\text { GOLF Siga en vivo el desenlace de la Ryder Cup } \gg\end{array}$}} \\
\hline & & \\
\hline elmundo.es " & elmundo.es Salud $n$ & Edición impresa " \\
\hline - Portada & - Medicina & - Primera \\
\hline 'España & - Cáncer & Opinión \\
\hline - Internacional & - Sida y Hepatitis & 'España \\
\hline - Economía & - Dolor & - Mundo \\
\hline Polsa & - Tabaquismo & - Ciencia \\
\hline - Mercados & - Neurociencia & - Economía \\
\hline $\begin{array}{l}\text { : Los que más } \\
\text { - Nacionales }\end{array}$ & - Mujer & - Motor \\
\hline - Internacionales & - Biociencia & - Deportes \\
\hline - Fondos de inversión & - Corazón & - Cultura \\
\hline - Recomendaciones & - Dudas y preguntas & - Comunicación \\
\hline ' Su cartera & - Sida y Hepatitis & - última \\
\hline $\begin{array}{l}\text { :El experto opina } \\
\text { Agenda económica }\end{array}$ & $\begin{array}{l}\text { " Cáncer } \\
\text { - Dolor }\end{array}$ & - Índice del día \\
\hline - Buscar empresas europeas & - Neurociencia & - Edición local \\
\hline - Cultura & - Mujer & M2 \\
\hline - Blog El escorpión & ' La semana & 'Baleares \\
\hline 'Blog, James Blog & 'Enfermedades & - Suplementos \\
\hline - Ciencia & - Gráficos & Magazine \\
\hline - Comunicación & 'Especiales & - Crónica \\
\hline
\end{tabular}

Indicador 4.6: acceso a la información a través de la recomendación de los usuarios

Definición: el medio de comunicación presenta al usuario una sección en la que el usuario puede conocer aquellas noticias que han tenido un mayor im- 
pacto entre los usuarios ya que han sido las más leídas, las más buscadas, las más vistas, las más enviadas por los usuarios, etc.

Examen: ¿puede el usuario conocer qué noticias han tenido un mayor impacto entre los usuarios de su sitio web?

Ejemplos: el sitio web del diario The Washington Post.

http://www.washingtonpost.com/wp-srv/most-popular.html?hpid=hcmodule

Procedimiento: examen del sitio web. Página de inicio.

Puntuación: 0-3.

Dimensión: acceso al contenido.

\section{FIGURA 19}

Sección dedicada a las noticias más populares entre los usuarios del sitio web del diario The Washington Post

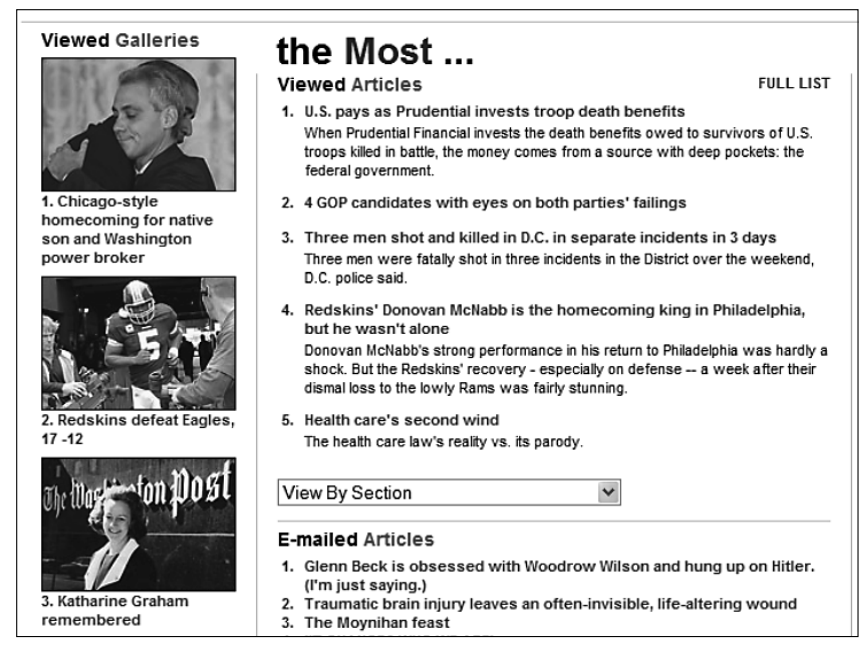

Indicador 4.7: acceso a la información a través de plataformas externas de la Web 2.0

Definición: el medio de comunicación facilita el acceso a sus informaciones a través de plataformas externas, propias de la Web 2.0. Esto permite que los usuarios accedan a la información de los medios de comunicación sin necesidad de visitar el sitio web del medio sino a través de las plataformas 2.0 que utilicen habitualmente.

Examen: ¿puede el usuario conocer noticias del medio de comunicación a través de plataformas externas de la Web 2.0?

Ejemplos: ejemplo de buena práctica: Periodismo Humano.

Procedimiento: búsqueda en Facebook.

Puntuación: 0-3.

Dimensión: acceso al contenido. 


\section{FIGURA 20}

Acceso a una noticia publicada por el medio de comunicación Periodismo Humano a través Facebook

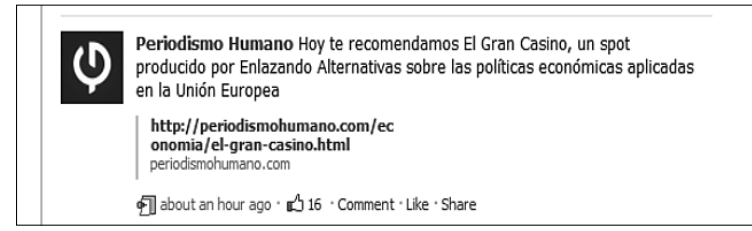

\section{PARÁMETRO 5: acceso a la información de forma personalizada}

Indicador 5.1: adaptación de la interfaz del sitio web del medio de comunicación en función de los contenidos de interés para el usuario

Definición: el medio de comunicación permite que el usuario tenga la posibilidad de seleccionar aquella información que le interesa y rediseñar con ella el sitio web. En algunos sitios web es necesario que el usuario se registre para llevar a cabo esta personalización de los contenidos. Esto permite que cada vez que el usuario visita el sitio web del medio como usuario registrado pueda acceder a su página de contenido personalizado.

Examen: ¿puede el usuario personalizar el contenido del sitio web del medio de comunicación con la información que resulta de su interés?

Ejemplos: el sitio web del canal de televisión $B B C$, que sin necesidad de estar registrado permite que el usuario añada o quite secciones en función de su interés particular.

http://www.bbc.co.uk/

Procedimiento: examen del sitio web. Página de inicio.

Puntuación: 0-3.

Dimensión: acceso al contenido.

\section{FIGURA 21}

El sitio web de la BBC permite que sus usuarios personalicen su interfaz

\begin{tabular}{|l|l|}
\hline More Top Stories & Edit $\times$ \\
Mumbai accused says \\
ready to die
\end{tabular}


Indicador 5.2: sindicación de contenidos del medio de comunicación a través del móvil o correo electrónico

Definición: el usuario tiene la opción de suscribirse al servicio de sindicación de contenidos (RSS) para recibir a través del teléfono móvil, el correo electrónico, su blog, o su página de iGoogle, información publicada sobre los temas que sean de su interés.

Examen: ¿puede el usuario suscribirse a servicios de sindicación de contenidos de la temática que le interesa a través del soporte (móvil o correo electrónico) que considere más conveniente?

Ejemplos: ejemplo de buena práctica: Sitio web del diario $A B C$.

http://www.abc.es/

Procedimiento: examen del sitio web. Página de inicio.

Puntuación: 0-3.

Dimensión: acceso al contenido.

FIGURA 22

Acceso a los canales de contenido sindicado del diario ABC

\section{Alertas SMS Registro Newsletter Hemeroteca RSS \&}

\section{Indicador 5.3: suscripción de alertas o boletín electrónico}

Definición: el usuario tiene la opción de suscribirse al servicio de alertas o boletín electrónico del sitio web del medio de comunicación para recibir por correo electrónico o móvil aquellas noticias que el medio publique sobre la temática que le interese.

Examen: ¿puede el usuario suscribirse a servicios de newsletter (móvil o correo electrónico)?

Ejemplos: sitio web del diario El País.

https://plus.elpais.com/clientes2/registro/registroUsuario.html?prod=TIT

Procedimiento: examen del sitio web. Página de inicio.

Puntuación: 0-3.

Dimensión: acceso al contenido. 


\section{FIGURA 23}

El diario El País ofrece al usuario la opción de activar las Newsletters en las que esté interesado

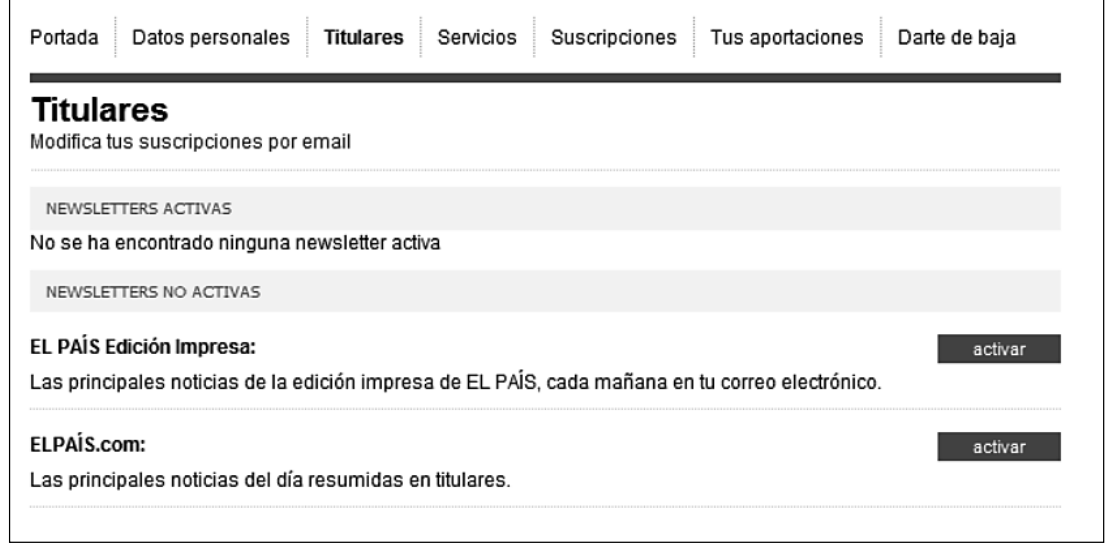

\section{PARÁMETRO 6: el medio ofrece distintas versiones de su información}

\section{Indicador 6.1: versión impresa del medio}

Definición: en el caso de los diarios en línea, el medio de comunicación permite que el usuario lea la información tal y como aparece en su versión impresa. Esto significa que el usuario puede visualizar las diversas secciones que contiene el diario impreso, la visualización del alzado total de páginas que componen el diario impreso y el acceso directo e independiente a cada una de las páginas. Asimismo, el lector puede hacer zoom en cada una de las páginas, descargarlas e imprimirlas. No es necesario que el usuario se registre en el medio de comunicación para acceder a este tipo de versión.

Examen: ¿puede el usuario leer en la pantalla de su ordenador el diario tal y como aparece en su versión impresa?

Ejemplos: la versión impresa del diario El País.

http://www.elpais.com/diario/

Procedimiento: examen del sitio web. Página de inicio.

Puntuación: 0-3.

Dimensión: acceso al contenido. 
FIGURA 24

Versión impresa del diario El País

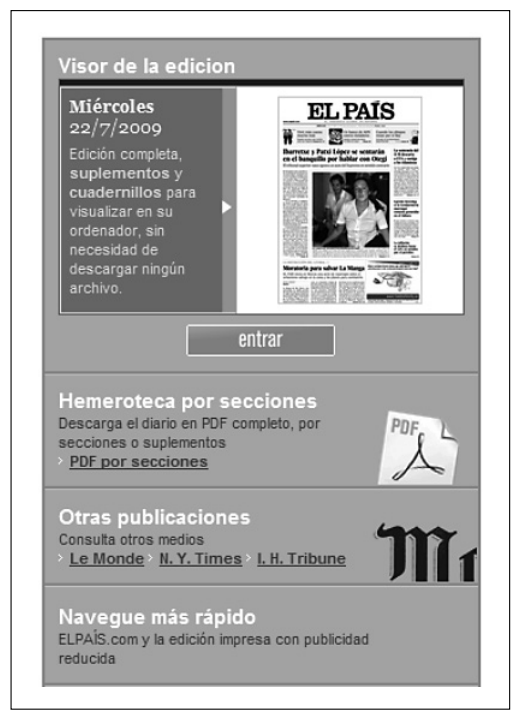

\section{Indicador 6.2: versión global del medio de comunicación}

Definición: la versión global del medio permite al usuario acceder a un tipo de versión en el que se facilita el acceso a través de enlaces a otros medios de comunicación. Gracias a esto, el usuario puede ver cómo han sido tratadas las noticias en otros medios de comunicación.

Examen: ¿se permite al usuario acceder a una versión global del medio de comunicación en el que se facilitan un mayor número de enlaces a medios externos?

Ejemplos: la versión global del diario The New York Times.

http://global.nytimes.com/

Procedimiento: examen del sitio web. Página de inicio.

Puntuación: 0-3.

Dimensión: acceso al contenido.

FIGURA 25

Versión global del diario The New York Times

\section{GLOBAL EDITION

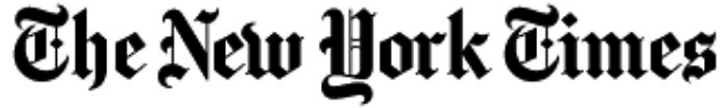

WITH THE International Hieralo Eribune 


\section{Indicador 6.3: versión actualizada de forma constante}

Definición: el medio de comunicación pone a disposición del usuario una versión donde las informaciones aparecen ordenadas en orden descendiente en función de su actualización. El medio indica de forma detallada la hora en la que se ha realizado la última actualización y especifica el número de actualizaciones que se hacen en un día o un número concreto de horas.

Examen: ¿puede el usuario leer una versión donde aparezcan las informaciones que se han actualizado de forma más reciente y se facilite la hora de actualización?

Ejemplos: la versión wire del diario The New York Times.

http://www.nytimes.com/timeswire/index.html

Procedimiento: examen del sitio web. Página de inicio.

Puntuación: 0-3.

Dimensión: acceso al contenido.

\section{FIGURA 26}

Indicación del grado de actualización de las noticias en el diario The New York Times

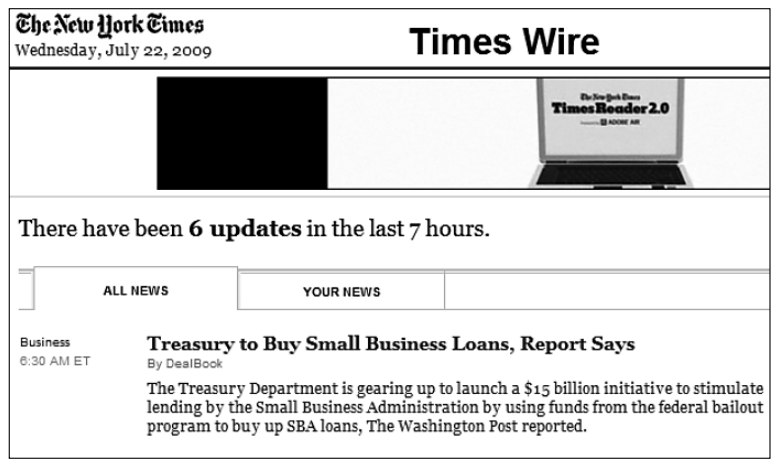

\section{Indicador 6.4: versión impresa adaptada a la Web}

Definición: el medio de comunicación pone a disposición del usuario una versión impresa del diario con la particularidad de que se actualiza con la misma rapidez que lo hace la versión online.

Examen: ¿puede el usuario leer una versión impresa del diario que es actualizada al ritmo que la versión en línea?

Ejemplos: la versión 2.0 del diario The New York Times.

Procedimiento: examen del sitio web. Página de inicio.

http://timesreader.nytimes.com/webapp/TimesReader.do?promoCode=T9179X QW1\&campaignId=37483

Puntuación: 0-3.

Dimensión: acceso al contenido. 


\section{FIGURA 27}

The New York Times dispone de una versión electrónica, con el mismo formato de la versión impresa, actualizado al último minuto

Welcome to the future. Your newspaper is here.

It reads like a newspaper. Updates like a Web site. And delivers like The New York Times. The new Times Reader 2.0 delivers the entire day's Times in seconds,

\section{PARÁMETRO 7: empleo de herramientas de la Web 2.0}

\section{Indicador 7.1: compartir información con otros usuarios}

Definición: este recurso facilitado por el medio de comunicación permite al usuario compartir aquellas informaciones que resulten de su interés con otros usuarios utilizando herramientas propias de la Web 2.0.

Este tipo de herramientas comprenden diversos tipos de sitios, plataformas y servicios web del entorno de la Web 2.0, entre otros:

- Redes sociales de amistades o profesionales, como Facebook o LinkedIn, a través de las que el usuario se pone en contacto con otros usuarios.

- Sitios webs tipo menéame, delicious, MySpace, Technorati, msn reporter, Google bookmarks, o Twitter.

Para hacer uso de estas herramientas el usuario debe estar registrado

Examen: ¿permite el medio de comunicación que el usuario comparta con otros usuarios a través de herramientas 2.0 las informaciones que sean de su interés?

Ejemplos: el sitio web del diario El Mundo.

Procedimiento: examen del sitio web. Página donde aparece publicado el texto completo del artículo. http://www.elmundo.es/elmundo/2009/07/21/ciencia/1248173151.html

Puntuación: 0-3.

Dimensión: cooperación.

FIGURA 28

Servicios y herramientas de la Web 2.0 incluidos en el diario El Mundo

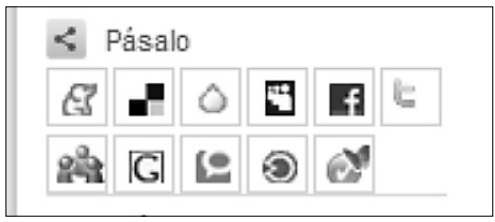




\section{Indicador 7.2: blogs vinculados al medio de comunicación}

Definición: el medio de comunicación cuenta con blogs de diferentes temáticas firmados por miembros de su equipo de redacción.

Examen: ¿dispone el medio de comunicación de blogs firmados por miembros de la redacción o colaboradores?

Ejemplos: el sitio web del diario El País.

Procedimiento: examen del sitio web. Sección llamada Blogs.

http://www.elpais.com/blogs/

Puntuación: 0-3.

Dimensión: acceso al contenido.

FIGURA 29

Sección dedicada a blogs creados y actualizados por miembros de la redacción o colaboradores del diario El País

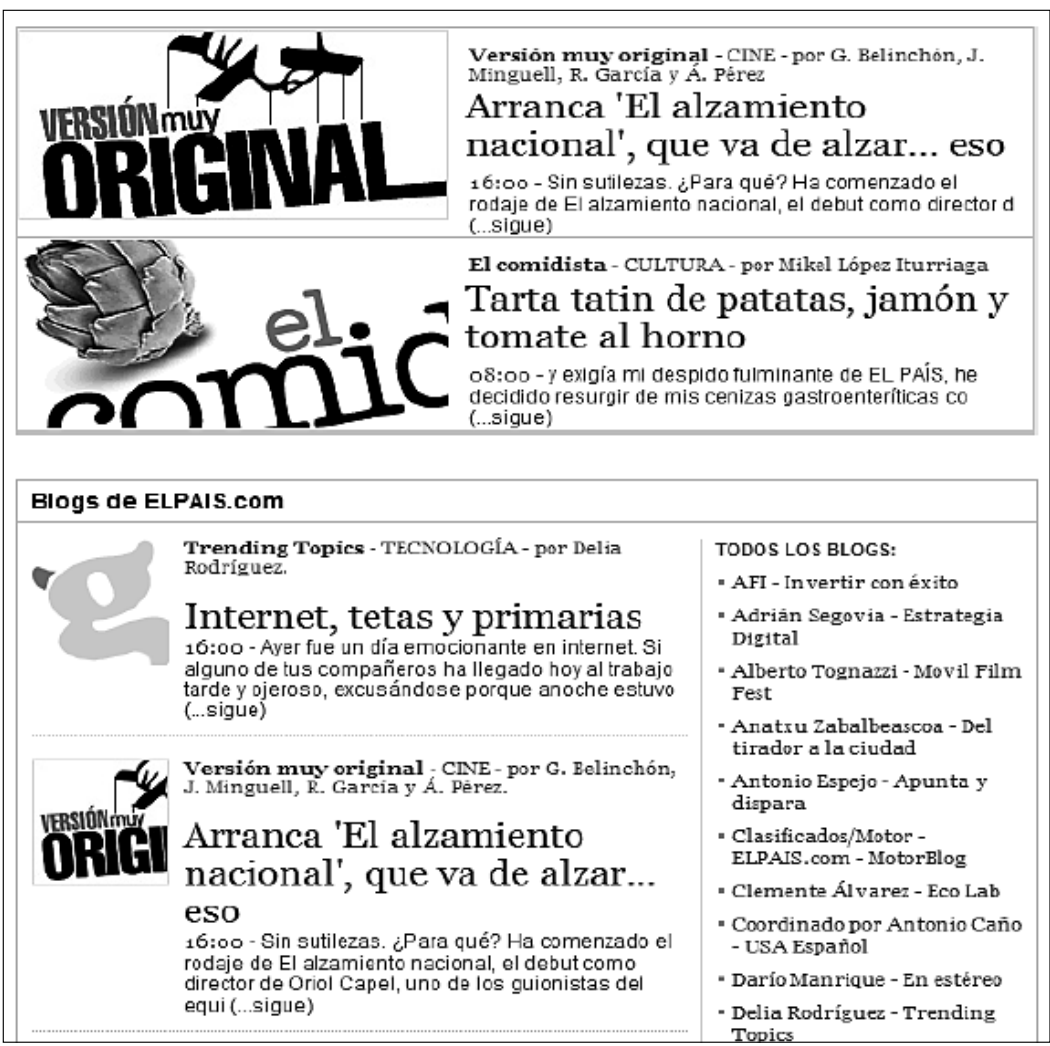




\section{PARÁMETRO 8: plataformas de la web 2.0 en las que tiene presencia el medio de comunicación}

\section{Indicador 8.1: presencia del medio de comunicación en plataformas audiovisuales}

Definición: el medio de comunicación hace uso de sitios web externos para difundir la información que produce entre los usuarios de dichos sitios web. Un tipo de plataforma de la Web 2.0 que emplean los medios de comunicación son aquellos sitios web que gozan de gran popularidad y proveen contenido audiovisual. Estos sitios web sirven de canal al medio de comunicación para difundir los vídeos que produce.

Examen: ¿hace uso el medio de comunicación de sitios web especializados en la difusión de vídeos para canalizar el material audiovisual que produce?

Ejemplos: el canal de televisión PBS en Youtube. Permite que los usuarios conozcan cuáles son los vídeos más vistos y los más comentados. El usuario puede suscribirse al canal y comentar cada uno de los vídeos.

http://www.youtube.com/user/PBS

Procedimiento: examen del sitio web. Página de inicio.

Puntuación: 0-3.

Dimensión: comunicación.

FIGURA 30

Canal en Youtube del canal de televisión PBS

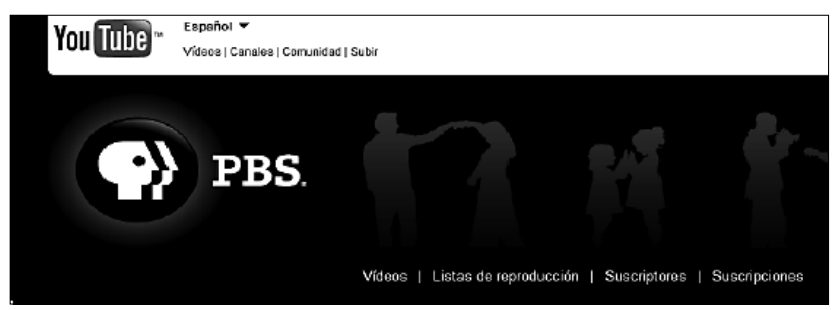

\section{Indicador 8.2: presencia del medio de comunicación en plataformas de imágenes}

Definición: el medio de comunicación hace uso de sitios web externos para difundir la información que produce entre los usuarios de dichos sitios web. Las plataformas de la Web 2.0 especializadas en la difusión de material fotográfico e imágenes, y que cuentan con gran popularidad entre los usuarios, son utilizadas por los medios de comunicación para publicar el archivo de material fotográfico del que disponen o que le hacen llegar sus lectores.

Examen: ¿emplea el medio de comunicación plataformas 2.0 especializadas en la publicación de fotografías para difundir su material fotográfico? 
Ejemplos: el canal del diario The Guardian en Flickr.

Procedimiento: examen del sitio web. Página de inicio.

Puntuación: 0-3.

Dimensión: comunicación.

\section{FIGURA 31}

El diario The Guardian posee canales en flickr para contextualizar ciertas noticias mediante imágenes propias o de sus lectores
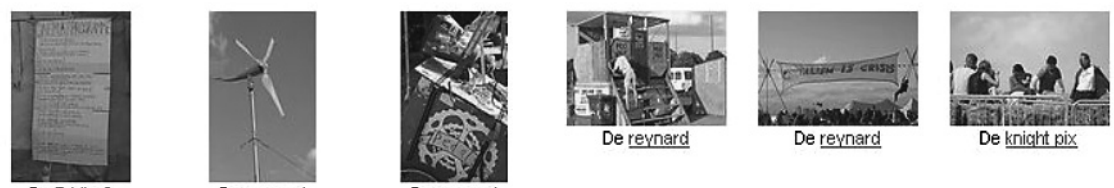

De Eddie C

De reynard

De reynard

De revnard

De knight pix

The Guardian on Flickr (administrador del grupo) dice:

25 de ago 09 - It's summer camp once again as Camp for Climate Action gather to raise awareness of the issues at stake ahead of the much anticipated Copenhagen climate talks. Are you taking part or have you captured a passing protest? Share your photos of climate camping in this group

\section{Indicador 8.3: Empleo de redes sociales propias}

Definición: el medio de comunicación cuenta con una red social propia que hace posible que la cobertura de ciertas noticias se haga a través de las aportaciones de los periodistas vinculados al medio y también de los usuarios. Para poder formar parte de esta red social propia el usuario debe estar registrado y completar su perfil. Los usuarios pueden seguir la información de los temas que sean de su interés, de los temas en los que participen y de las reacciones que se deriven de sus colaboraciones.

Examen: ¿cuenta el medio de comunicación con una red social propia en la que periodistas y usuarios participen en la cobertura de las noticias?

Ejemplos: Eskup, del sitio web del diario El País.

http://eskup.elpais.com/Estaticas/ayuda/quees.html

Procedimiento: examen del sitio web. Página de inicio.

Puntuación: 0-3.

Dimensión: socialización. 


\section{FIGURA 32}

Imagen de la cobertura realizada por Eskup, la red social propia del diario El País

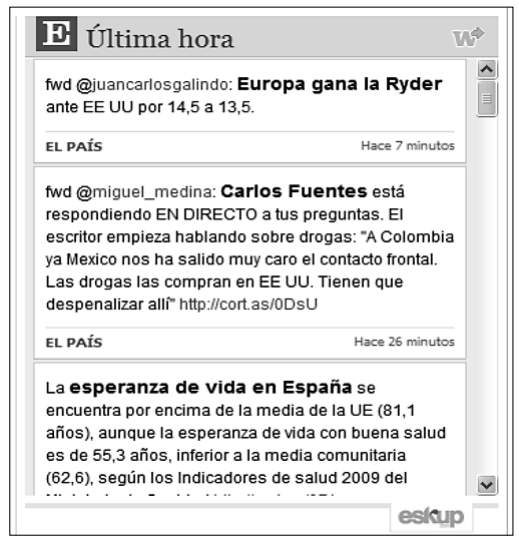

\section{Indicador 8.4: presencia del medio de comunicación en redes sociales profesionales externas}

Definición: el medio de comunicación atrae y fideliza usuarios a través de los sitios webs de redes sociales profesionales más populares en el entorno de la Web 2.0, como son LinkedIn o Xing.

Examen: ¿hace uso el medio de comunicación de los sitios web de redes sociales profesionales para atraer y fidelizar a sus usuarios?

Ejemplos: perfil del diario El País en la red social profesional LinkedIn.

Procedimiento: examen del sitio web. Página de inicio.

Puntuación: 0-3.

Dimensión: socialización.

\section{FIGURA 33}

Presencia del diario El País en la red social de carácter profesional LinkedIn

\begin{tabular}{|c|c|}
\hline Companies ЕЕтศ & Comparies Home | Add Company | FAQ \\
\hline El Pais & Last edited by Head eBusiness \\
\hline \multirow{3}{*}{$\begin{array}{l}\text { El Pais is Spain's most widely circulated and most } \\
\text { influential newspaper and is respected worldwide. It was first published on May } \\
4,1976 \text {, just as Spain was beginning the transition to democracy. The paper's } \\
\text { vigorous defense of civil liberties and its support for political and social change, } \\
\text { quickly made it an icon of modern Spain. }\end{array}$} & \\
\hline & Related Companies \\
\hline & $\begin{array}{l}\text { Career path for El Pais employees } \\
\text { before: } \\
\text { - Prisacom }\end{array}$ \\
\hline EI Pais was a pioneer in the adoption of... see more & $\begin{array}{l}\text { El Pais employees are most connected to: } \\
\text { - Prisacom }\end{array}$ \\
\hline $\begin{array}{l}\text { Current Employees (129 total) } \\
\text { Koyounian Noemi, Diseñadora gráfica }\end{array}$ & $\begin{array}{l}\text { - Vocento } \\
\text { • Público }\end{array}$ \\
\hline Fernando Peinado Alcaraz, Journalist & See more » \\
\hline
\end{tabular}




\section{Indicador 8.5: presencia del medio de comunicación en redes sociales} de amistad

Definición: el medio de comunicación atrae y fideliza usuarios haciendo uso de las redes sociales de amistad que cuentan con mayor popularidad entre los internautas. Este tipo de sitios web permite al medio de comunicación conocer, entre otras, los siguientes aspectos:

- número y perfil de los usuarios interesados en los contenidos que produce,

- difusión entre los usuarios de información constante respecto a estos contenidos,

- opinión de los usuarios sobre los contenidos.

Examen: ¿utiliza el medio de comunicación de sitios web de redes sociales para establecer contacto con sus usuarios?

Ejemplos: canal de televisión TVE1 en Facebook.

http://www.facebook.com/s.php?ref=search\&init=quick\&q=tve\%201\&_a=1\#/ group.php?gid=40929076798\&ref=search

Procedimiento: búsqueda en Facebook.

Puntuación: 0-3.

Dimensión: socialización.

FIGURA 34

Perfil del canal de televisión TVE 1 en la red social facebook

\begin{tabular}{|l|l|}
\hline facebook Home Profile Friends Inbox 13 \\
\hline $\begin{array}{l}\text { Global } \\
\text { TVE } 1\end{array}$ \\
$\begin{array}{l}\text { Type: } \\
\text { Description: }\end{array}$ \\
$\begin{array}{l}\text { Entertainment \& Arts - Television } \\
\text { Grupo destinado a agrupar a todos aquellos a quienes les gusta TVE 1. Nació en } \\
\text { momentos mente ya ha alcanzado los cincuenta años de vida dejándonos } \\
\end{array}$ \\
\hline
\end{tabular}

Indicador 8.6: presencia del medio de comunicación en plataformas de microblogging

Definición: el medio de comunicación hace uso de sitios web externos para difundir la información que produce entre los usuarios de dichos sitios web. Un ejemplo de este tipo de sitios web son las plataformas de microblogging, que cuentan con un gran número de usuarios registrados y les permiten publicar de forma constante textos de limitada extensión con contenido referente a noticias 
de última hora. Los textos que se publican en este tipo de sitios web son redactados en exclusiva para ellos.

Examen: ¿utiliza el medio de comunicación plataformas de microblogging para difundir las informaciones que produce?

Ejemplos: el uso que hace el sitio web del canal de televisión Discovery en Twitter.

http://twitter.com/tudiscovery

Procedimiento: examen del sitio web.

Puntuación: 0-3.

Dimensión: comunicación.

FIGURA 35

Canal de microblogging del canal de televisión Discovery en Twitter

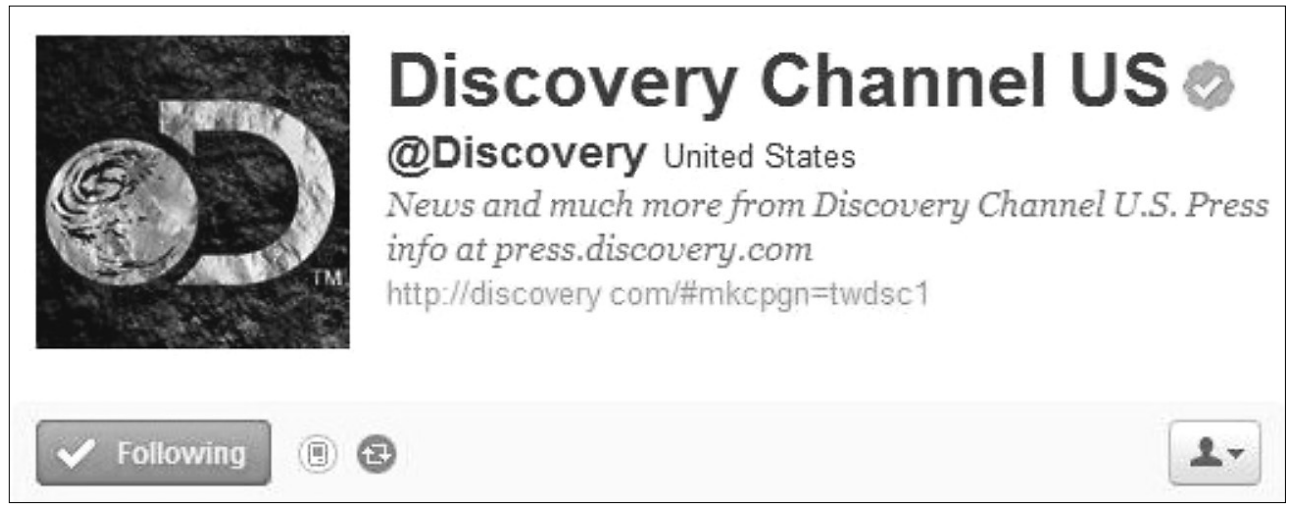

Indicador 8.7: vinculación entre el sitio Web del medio de comunicación y las plataformas sociales

Definición: el medio de comunicación incorpora iconos en su sitio web para informar a sus usuarios de su presencia en plataformas sociales. De esta manera, los usuarios pueden utilizar las plataformas sociales para compartir el contenido proporcionado por el medio de comunicación.

Examen: ¿cuenta el medio con iconos clicables que permiten a sus usuarios saber que está presente en plataformas sociales?

Ejemplos: el uso que hace el sitio web del diario El País.

http://www.elpais.com/articulo/internacional/guerra/Libia/agota/

Europa/elpepiint/20110622elpepiint_1/Tes

Procedimiento: examen del sitio web. Página donde aparece publicado el texto completo del artículo.

Puntuación: 0-3.

Dimensión: comunicación. 
FIGURA 36

Vinculación entre el sitio Web del medio de comunicación $y$ las plataformas sociales

La guerra en Libia

La guerra en Libia agota a Europa

Los países aliados dudan sobre la legitimidad y el coste de la intervención militar - Los europeos quieren la respaldan una misión terrestre

RICARDO MARTÍNEZ DE RITUERTO - Bruselas - 22/06/2011

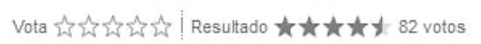

G ic (i) $\mathcal{G}:$ Twittear $\{72$

Frecommend $<152$

\section{Conclusiones}

Debido a la consolidación de la web como uno de los escenarios más utilizados para la búsqueda y el acceso a la información (Johnson, 2006), los medios de comunicación han considerado necesario adaptar sus contenidos y estrategias de comunicación a este nuevo entorno.

Pero conocer cuáles son las mejores herramientas y estrategias de comunicación no resulta fácil ya que es complicado determinar el impacto de su uso de algunas de estas herramientas y, sobre todo, su perdurabilidad en el entorno web.

Con el fin de ayudar a resolver esta problemática y establecer una pauta que permita conocer si un medio de comunicación hace buen uso o no de las tecnologías más consolidadas y de mayor impacto en la web, este artículo propone y define un conjunto de 36 indicadores que permiten evaluar la calidad de la interacción de sitios web de los medios de comunicación.

Entre otros propósitos, esta propuesta pretende poner en manos de los profesionales de los medios de comunicación una metodología que les permita identificar cuáles son las herramientas, servicios y estrategias de comunicación que garantizan que sus informaciones lleguen de forma adecuada a sus usuarios así como evaluar la calidad de los sitios web de sus medios de comunicación.

\section{Agradecimientos}

Esta investigación ha sido financiada parcialmente por los proyectos "Evolución de los cibermedios españoles en el marco de la convergencia. Análisis del mensaje (Ref. CSO 2009-13713-C05-04)" y "Nuevas estrategias de publicidad y promoción de las marcas turísticas españolas en la web (Ref. CSO 2008-02627)", del Ministerio de Ciencia e Innovación (España).

\section{Bibliografía}

Bradshaw, P. (2008). How interactive are UK business news websites? Online Journalism Blog, April 7. [En línea] <http://bit.ly/fXusoY> [consulta: 11/04/2011]. 
Codina, L. (2000). Evaluación de recursos digitales en línea. Revista Española de Documentación Científica, v. 23, n. 1, 9-44.

Codina, L. (2006). Evaluación de calidad en sitios web: Metodología de proyectos de análisis sectoriales y de realización de auditorías. Barcelona; Universidad Pompeu Fabra, Área de Biblioteconomía y Documentación, p. 13 [En línea] <http://www.lluiscodina. $\mathrm{com} / \mathrm{metodos} /$ procedimientos2006.doc> [consulta: 12/04/2011],

Díaz Noci, J. (2005). Periodismo en Internet: Investigar los nuevos medios. En: Xosé López García, Xosé Pereira, Xosé Villanueva (editores) Investigar sobre periodismo: Reunión científica de la Sociedad Española de Periodística (SEP). Santiago de Compostela; Universidade, Servizo de Publicacións e Intercambio Científico, 74-100.

Díaz Noci, J. y otros. (2009). Content and message analysis of online journalism: some methodological proposals. Proceedings of the VInternational Conference: Comunication and Reality, 647-656, Trípodos [Extra 2009].

Geary, J. (2008) Interaction on business news websites (Infografía). [En línea] <http://bit. ly/eOby5t> [consulta: 11/04/2011].

Glocer, T. (2006). Old media must embrace the amateur. Financial Times, published: March 8. [En línea] <http://on.ft.com/gFBM6s> [consulta: 20/03/2011].

Guallar, J., y Abadal, E. (2009). Evaluación de las hemerotecas de prensa digital: indicadores y ejemplos de buenas prácticas. El profesional de la información, 2009, mayojunio, v. 18, n. 3, 255-269.

Horrigan, J. B. (2006). For many home broadband users, the internet is a primary news source (Technical report). Washington, DC; Pew Internet and American Life Project, p. 27. [En línea] <http://bit.ly/tTfqZN> [consulta: 10/12/2011].

Johnson, B. (2006). Google News under fire. The Guardian, published: March 2. [En línea] $<$ http://bit.ly/hKgUWN> [consulta: 11/04/2011].

López García, G. (ed.) (2008). Comunicación local y nuevos formatos periodísticos en Internet: cibermedios, confidenciales y weblogs. Valencia; Servei de Publicacions de la Universitat de València, p.208. [En línea] <http://bit.ly/gmbXSs> [consulta: 11/04/2011].

Meso, K., y Palomo, B. (2008). Los blogs de autor en los ciberdiarios de referencia españoles. Prisma.com, n. 7. [En línea] <http://bit.ly/h4uLox> [consulta: 11/04/2011].

Palacios, M., y Díaz Noci, J. (eds.) (2009). Online Journalism: Research Methods: A multidisciplinary approach in comparative perspective. Bilbao; Servicio Editorial de la Universidad del País Vasco, p. 178. [En línea] <http://bit.ly/edPQFD> [consulta: 11/04/2011].

Pew Research Center (2011). The State of the News Media 2011: Online (Technical report). [En línea] <http://bit.ly/gmbXSs> [consulta: 11/04/2011].

Rodríguez-Martínez, R., y Pedraza-Jiménez, R. (2009). Prensa digital y Web 2.0. Hipertext. net, n. 7. [En línea] <http://bit.ly/fHPpZo> [consulta: 11/04/2011].

Rodríguez-Martínez, R.; Codina, L., y Pedraza-Jiménez, R. (2010). Cibermedios y web 2.0: modelo de análisis y resultado de aplicación. El profesional de la información, v. 19, n. $1,35-44$.

Salaverría, R. y otros. (2005). Spain: Multimedia Richness and variety of business models. En: Richard van der Wurff, Edmund Lauf, John O'Sullivan (eds.) Print and Online Newspapers in Europe: A Comparative Content Analysis in 16 countries in Western and Eastern Europe. Amsterdam: Het Spinhuis, 231-244. 
Schutz, T. (1999). Interactive options in Online Journalism: A Content Analysis of 100 U.S. Newspapers. Journal of Computer Mediated Communication, 5 (1). [En línea] <http:// bit.ly/eKqbUO> [consulta: 11/04/2011].

The Bivings Group (2008). The Use of the Internet by America's Largest Newspapers (2008 Edition) (Technical report). [En línea] <http://bit.ly/gJr4mo> [consulta: 11/04/2011].

Wurff, R.; Lauf, E., y O'Sullivan, J. (eds.) (2005). Print and Online Newspapers in Europe: A Comparative Content Analysis in 16 countries in Western and Eastern Europe. Amsterdam: Het Spinhuis, p. 326.

Zamith, F. (2008). Ciberjornalismo: As potencialidades da Internet nos sites noticiosos portugueses. Porto; Afrontamento, p. 113. 